\title{
COLD CHAIN AND ITS IMPORTANCE
}

\author{
Olivia Churchman
}

\section{INTRODUCTION}

Cold chain management is a process that is vitally important within contemporary healthcare. Health and wellbeing are strongly linked to appropriate immunisation and complete immunity. The World Health Organization (WHO) (2020a) defines immunisation as "a process whereby a person is made immune or resistant to an infectious disease, through administration of a vaccine" (p.l). In order for vaccinations to be safely administered, they must be appropriately handled and transported to maintain a continuous stable and optimum state, through an intrinsic process known as 'cold chain'. The WHO (2020b) identifies cold chain as system in which various professionals are involved in handling and transporting vaccines, from manufacture up until they are administered, at optimum temperatures between two and eight degrees celsius in order to maintain vaccine potency and stability.

Cold chain is a highly collaborative process, dependent on each person to uphold duteously their given responsibility throughout the process. Collaboration exists on transforming segregated individual tasks into meaningful interprofessional obligations, during which the reduction of harm and the promotion of health is fundamental. It is the concept of caring that differs nursing from other professions. With a caring culture, healthcare professionals see every team member as an intricate piece of a whole, one cannot exist without the other. This publication demonstrates that an atmosphere that meets team members' individual needs and binds healthcare professionals together, can only exist through inter-professional collaboration (Wei, Corbett, Ray, \& Wei, 2020).

Currently in New Zealand (NZ) there is still a record number of incidents whereby the cold chain process is broken, and vaccines destabilise leading to ineffective immunisation. There is considerable evidence to demonstrate that the current protocols for cold chain management in NZ are not effective and are endangering the lives and trust between patients and health professionals. In a report published by the Ministry of Health (2018a) statistics showed there had been an excess of excursions, whereby a vaccine is out of its optimum temperature range for too long, and irreversible damage has occurred to the potency and stability of the vaccine. It is estimated that one medium-sized fridge or chilly bin containing an appropriate amount of vaccines will cost more than $\$ 8,000$ to replace after an excursion has occurred. This is clearly a critical issue, resulting in adverse effects for every single person in NZ when the cold chain process is not strictly adhered to. The literature review allowed an opportunity to research where the process is currently broken and to develop strategies that will enable the process to be more safe, efficient, and collaborative.

\section{EVIDENCE AND FINDINGS}

\section{Cold Chain Protocol Implementation}

Current evidenced-based research available within NZ, during the time period in which cold chain was first introduced until the present, demonstrates a significant gap within effective cold chain processes and protocols nationally. New Zealand has only recently developed the National Standards for Vaccine Storage and Transportation 
for Immunisation Providers (Ministry of Health, 2017). This was the first policy to be published in relation to regulating the cold chain process within New Zealand. However, there are limited studies within NZ dating back to the early 1990s in association with the cold chain have been published. Therefore, it can be concluded that NZ has been undertaking practices that are not regulated nor evidenced-based.

Studies investigating the cold chain protocols for vaccines within NZ focussed primarily on assessing the effectiveness of cold chain processes. Four studies found that current cold chain processes do not ensure the stability and potency of vaccines from manufacturer to when they are administered (Clancy, Karish, Roddy, Sicilia, \& Bigham, 2017; Hazelton, Balcomb, Bowd, Hazelton-Parsons, \& Liddle, 2002; Nursing Review, 201I; Turner, Laws, \& Roberts, 20II). A document published by the Ministry of Health (2016) reviewing cold chain practices and management at a national level identified current cold chain protocols as a "significant issue and an area that needs urgent improvement in the future" (p.2). This is a critical issue as it impedes on the integrity of herd immunity and the 95 percent National Immunisation Target set by the Ministry of Health (20।8b).

Whilst not every study focused on the effectiveness of cold chain protocols, several identified the need for more comprehensive guidelines and planning surrounding cold chain. From a public health perspective, this would enable a decreased risk of errors, the prevention of cold chain breaches, excursions and failures and an increase in safety when storing, handling and administering vaccines (Chiodini, 2014; Clancy et al., 2017; Kosari et al., 2018; Ministry of Health, 2016; Turner et al., 20II). However, it is also important to note that some studies also investigated education programmes surrounding cold chain prractices yet did not identify significant changes following programme implementation (Datkuliak \& Chichester, 20I4; Hazelton et al., 2002; Thielmann, Viehmann, \& Weltermann, 2015). This may be due to the education programme not being tailored to everyone's learning style. It may also be that despite the implementation of the education programme, protocols within the healthcare setting were still lacking the comprehensive processes needed in order to achieve change as was the case in one particular study (Thielmann et al., 20I5). This demonstrates the need for ongoing education that is tailored to specific clinical settings and the implementation of comprehensive cold chain protocols that will be effective and optimise processes within practice.

\section{Cold Chain Procedures in New Zealand}

Five studies investigating errors in the storage, handling and administration found that vaccines were often exposed to temperatures outside of their optimum range. One study in particular found that in one bulk transportation of vaccines, 20 percent of freeze-sensitive vaccines and eight percent of heat-sensitive vaccines had been exposed to temperatures out of range. Research estimates that in NZ this leads to a loss of $\$ N Z 4$ million annually, with 73 percent of this cost related to preventable incidents within practice.

Vaccine vials that are exposed to suboptimal temperatures develop microscopic cracks as a result of volume expansion resulting in bacterial contamination. This can lead to local or systemic infection within the recipient (Chiodini, 2014; Purssell, 2015; Smith, 2019; Turner et al. 2011; Youssef, Mearkle, \& Ford, 2020). Vaccines in NZ are imported from Australia and are then stored in Porirua at the national vaccine store. They are then sent by ProPharma to eight stores regionally from where they are delivered to general practices (Nursing Review, 20II). Inadequate storage of vaccines occurred within general practice in 49 percent of cases, during transportation in 46 percent of cases, and within the vaccine store in five percent of cases (Turner et al., 20II).

\section{DISCUSSION AND IMPLICATIONS FOR PRACTICE}

Ineffective cold chain protocols pose detrimental implications within public health. Inappropriate management of cold chain can result in reduced potency of vaccines leading to a lowered immune response and therefore poor protection against severe and life-threatening diseases, for example measles and meningitis (Youssef et al., 2020). 
Cold chain failures which result in individuals needing to be re-immunised can cause a lack of trust and complicate the relationship between the individual and healthcare practitioner. This therefore affects herd immunity and poses wide-reaching risks within the community (Chiodini, 20I4; Purssell, 2015; Smith, 2019). New Zealand primary health and public health nurses are predominantly responsible for ensuring the cold chain processes of vaccine storage, handling and administering are adhered to (Immunisation Advisory Council, 2019).

Therefore, it should be mandatory that adequate protocols are implemented in clinical settings that are appropriate for registered nurses to practise safely and provide vaccines. This will also enable adequate monitoring, education and quality improvement surrounding cold chain in association with their scope of practice as defined by the Nursing Council of New Zealand (20/2).

In a study published by Carr, Byles, and Durrheim (2017), research showed that practice nurses that were qualified to immunise were 98 percent more likely to uphold practices that ensured appropriate cold chain management. This study signified that registered nurses play an integral role in ensuring the optimal practices of cold chain protocols ultimately leading to a decreased risk in errors, the prevention of cold chain breaches, excursions and failures and an increase in both professional and patient safety. Registered nurses are in an ideal position to collaborate with patients and other healthcare professionals in order to implement national protocols at a local level in order to achieve effective cold chain processes.

It is also within a registered nurse's scope of practice at a societal level to advocate for change that will improve care provided to individuals and the population (Nursing Council New Zealand, 2012). Since it is clear that NZ does not currently have effective protocols that enable healthcare practitioners to provide safe, evidenced-based practice associated with cold chain, the need to formulate comprehensive protocols is essential. Primary health aims to promote, maintain and improve healthcare provided to individuals and the population with a specific focus on prevention (Ministry of Health, 2020). By reducing and ultimately preventing the significant risk factors for cold chain breaches, excursion and failures, improvement in practice safety, trust with healthcare practitioners and herd immunity can be achieved. Therefore, there is an obvious need for advocacy of a nationwide protocol.

\section{RECOMMENDATIONS AND RATIONALE}

\section{National Cold Chain Fact Sheet}

It is imperative that an evidenced-based factsheet is implemented within primary healthcare services associated with the cold chain protocol as defined by the National Standards for Vaccine Storage and Transportation for Immunisation Providers (Ministry of Health, 2017). The Ministry of Health (2016) states "there is a need to develop a more comprehensive guideline and factsheet for managing cold chain across a wide range of scenarios" (p.3). The six 'C's of Cold Chain are shown in Figure I, which is an evidenced-based factsheet that was recently developed to provide quick reference guidelines when practising cold chain within primary healthcare in order to provide more consistent, systemic care (Churchman, 2019). The six 'C's of Cold Chain include:

I. Comply with policies and understand your role within nationally documented protocols

2. Check all equipment is functioning up to the appropriate standards and is replaced before expiry

3. Consider the effects on the client and population if the cold chain process is not followed including reimmunisation, loss of herd immunity, an increase in preventable diseases and the loss of trust and confidence in the healthcare profession

4. Continuous monitoring of temperature should be used to ensure vaccines are strictly stored between $2^{\circ} \mathrm{C}$ and $8^{\circ} \mathrm{C}$ therefore reducing breaches, eliminating excursions and maintaining safety

5. Collect and document all information relevant to the cold chain process

6. Consult and inform relevant authority in the case of breaches, excursions or any situation in which impedes on the safety of the client, population or practitioner (Churchman, 2019). 


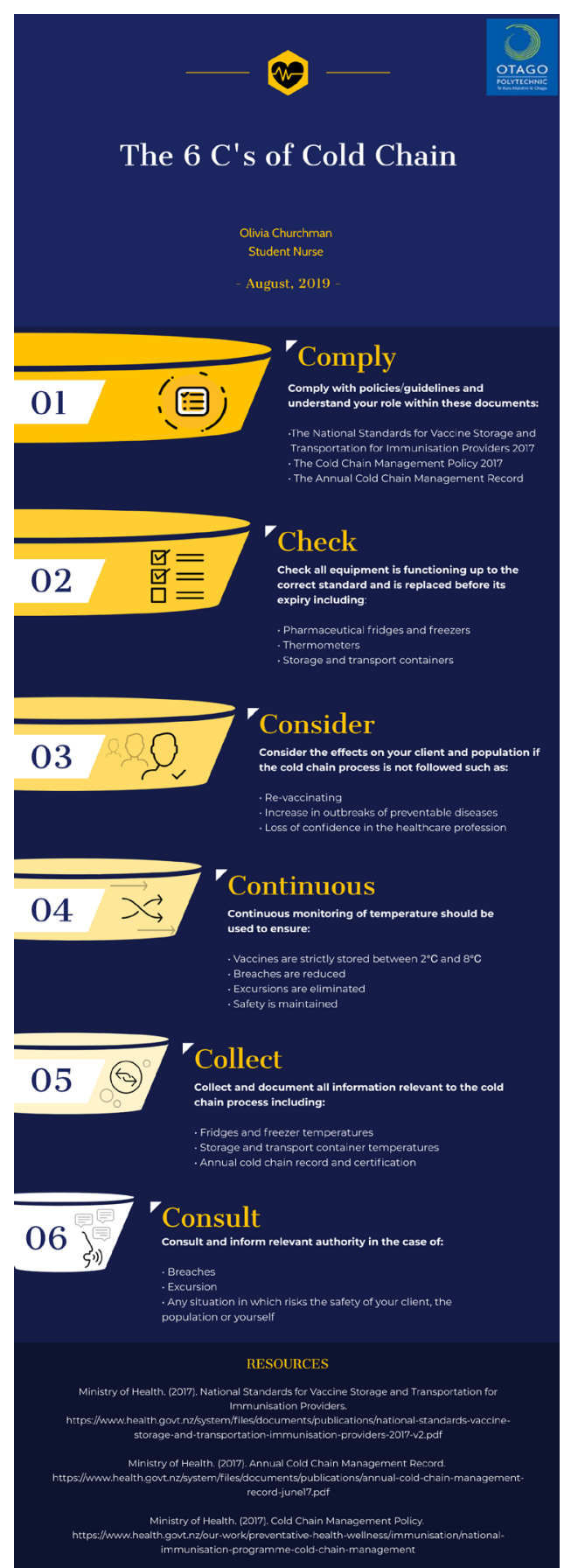

Figure I. The 6 'C's of Cold Chain Poster. Source: Olivia Churchman.
By implementing a nationwide quick reference factsheet, it enables the collaboration of healthcare practitioners throughout all regions in NZ therefore ensuring cold chain effectiveness, maintaining safety and improving evidenced-based nursing practice (Immunisation Advisory Council, 2020a; Ministry of Health, 2018c).

\section{National Education Programme}

It is crucial that a nationwide education programme be implemented in order for registered nurses and other healthcare practitioners to remain competent in association with their clinical and cultural skills. The Health Practitioners Competence Assurance Act 2003 requires health practitioners to uphold a continuity in education in order to obtain a standard of evidencedbased practice. The Immunisation Advisory Council (2020b) has recently implemented a cold chain vaccine storage and transportation education programme, however it is not mandatory to be completed by all individuals involved within the cold chain process. Increasing health practitioners' knowledge of policies and protocols throughout the cold chain process will improve their competency relevant to effective vaccine storage and transportation. This will reduce the risk of breaches, eliminate the potential for excursions and ensure the safety of the individual, population and practitioner (Purssell, 20I5; Turner et al., 20II). Collaboration of healthcare practitioners to provide interpersonal education with a multidisciplinary approach will allow for a broader understanding of the importance of the cold chain process in order to work together in the best interests of the individual and population (Datkuliak \& Chichester, 2014; Ministry of Health, 2018c).

\section{Expansion of Cold Chain Accreditation Model}

It is essential that a broader cold chain accreditation model is implemented in order to ensure vaccine potency and stability throughout every step in the cold chain process. The Ministry of Health (2016) states "the current cold chain accreditation model lacks frequency and scope as it focuses on policies in a clinical setting and does not include requirements for off-site clinics" (p.3). In order to provide culturally safe care to patients in a variety of settings, it is imperative registered nurses have the ability to practise in a safe 
manner that reduces any unnecessary risk to their patients and themselves as healthcare practitioners. Therefore, it is vital that they have access to evidenced-based protocols in order to uphold their responsibility (Nursing Council New Zealand, 20I2). Implementation of a more effective cold chain accreditation model will enable registered nurses to reach a broader range of individuals within the community. This will ultimately improve immunisations rates within public health while working in partnership as a collaborative profession to achieve the 95 percent Immunisation Target (Ministry of Health, 2016; Ministry of Health, 2018b).

\section{CONCLUSION}

Cold chain management is a process that is vitally important within contemporary healthcare. When the cold chain process is broken, there are detrimental implications for individuals and the population overall. In order to continue to improve the effectiveness of cold chain and the outcomes for patients, it is crucial nursing students, registered nurses and other healthcare professionals understand how to work in partnership using a collaborative multidisciplinary approach to provide the most appropriate education, prevention and practice measures. Only then will health practitioners be enabled to uphold effective cold chain procedures and perform in a unanimous, mellifluous manner that advocates for and promotes the health of New Zealand.

\section{Acknowledgements}

I would like to thank Mike Hammond and Jude Wall at Public Health Otago for their encouragement, support and partnership throughout the development of the initial 6C's of Cold Chain Poster. You challenged me to research a topic that I lacked any knowledge in which has enabled conversations that are so extremely important. I would also like to sincerely thank Laurie Mahoney at the Otago Polytechnic School of Nursing for her continued guidance, encouragement, and confidence. You believing in my small idea has grown into something so much bigger than I could have thought possible. Lastly, I would like to thank Jean Ross at the Otago Polytechnic School of Nursing for her oversight and support throughout the publishing process.

Olivia Churchman is a third-year nursing student currently undertaking a Bachelor of Nursing at Otago Polytechnic. Olivia began researching Cold Chain in New Zealand during her second year primary health clinical placement with Public Health Otago. By the completion of her clinical placement, Olivia had researched and developed the 6 C's of Cold Chain which was then distributed as a resource to Public Health Otago and the Immunisation Advisory Council. Olivia has continued to invest her interests and research into cold chain within New Zealand throughout her undergraduate education.

Correspondence to: Olivia Churchman, School of Nursing, Otago Polytechnic | Te Kura Matatini ki Otago, Forth Street, Private Bag 1910, Dunedin 9054, New Zealand. Email: olivia.churchman@gmail.com 


\section{REFERENCES}

Carr, C., Byles, J., \& Durrheim, D. (2017). Practice nurses best protect the vaccine cold chain in general practice. Australian Journal of Advanced Nursing, 27(2), 35-39. Retrieved from https://www.ajan.com.au/archive/Vol27/Carr.pdf

Chiodini, J. (20/4). Safe storage and handling of vaccines. Nursing Standard Journal, 28(25), 45-52. https://dx.doi.org/l0.7748/ ns20|4.02.28.25.45.e8486

Churchman, O. (2019). The 6 'C's of cold chain (poster). New Zealand: Otago Polytechnic.

Clancy, J., Karish, C., Roddy, M., Sicilia, J., \& Bigham, M. (2017). Temperature sensitive medications in interfacility transport: The ice pack myth. Air Medical Journal, 36(6), 302-306. https://doi.org/I0.1016/j.amj.2017.05.002

Datkuliak, D., \& Chichester, K. (2014). Keeping the cold chain strong through a multidisciplinary approach. American Academy of Ambulatory Care Nursing, 36(I), 4-9. Retrieved http://web.b.ebscohost.com.op.idm.oclc.org/ehost/detail/detail?vid=3\&sid=0a4el87c-b592$4 \mathrm{~b} 28$

Hazelton, K., Balcomb, A., Bowd, K., Hazelton-Parsons, D., \& Liddle, J. (2002). The immunisation cold chain: Why is it so hard to get right? Australian Family Physician, 3 ( (10), I -4. Retrieved from https://www.ncbi.nlm.nih.gov/pubmed/I2404833

Immunisation Advisory Council. (2019). Vaccination administration. Retrieved from https://www.immune.org.nz/health-professionals/ vaccine-administration-overview

Immunisation Advisory Council. (2020a). Cold chain. Retrieved from https://www.immune.org.nz/health-professionals/cold-chain

Immunisation Advisory Council. (2020b). Education and training. Retrieved from https://www.immune.org.nz/health-professionals/ education-training

Kosari, S., Walker, E., Anderson, C., Peterson, G., Naunton, M., Castillo-Martinez, E., Garg, S., \& Thomas, J. (20l8). Power outages and refrigerated medicines: The need for better guidelines, awareness and planning. Journal of Clinical Pharmacy and Therapeutics, 43(5), 737-739. https://doi.org/l0.11 II/jcpt. I27/6

Ministry of Health. (2016). National review of cold chain management practices: Summary and recommendations. Retrieved from https://www.health.govt.nz/our-work/preventative-health-wellness/immunisation/national-immunisation-programmecold-chain-management

Ministry of Health. (2017). National standards for vaccine storage and transportation for immunisation providers. Retrieved from https:// www.health.govt.nz/publication/national-standards-vaccine-storage-and-transportation-immunisation-providers-2017

Ministry of Health. (2018a). Immunisation updates. Retrieved from https://www.health.govt.nz/our-work/preventative-healthwellness/immunisation/updates-immunisation

Ministry of Health. (20l8b). Health targets: Increased immunisation. Retrieved from https://www.health.govt.nz/new-zealandhealth-system/health-targets/about-health-targets/health-targets-increased-immunisation

Ministry of Health. (2018c). National immunisation programme cold chain management. Retrieved from https://www.health.govt. nz/our-work/preventative-health-wellness/immunisation/national-immunisation-programme-cold-chain-management

Ministry of Health. (2020). Primary health care. Retrieved from https:/www.health.govt.nz/our-work/primary-healthcare?mega=Our\%20work\&title=Primary\%20health\%20care

Nursing Council New Zealand. (2012). Competencies for registered nurses. Retrieved from http://nursingcouncil.org.nz/Nurses/ Scopes-of-practice/Registered-Nurse

Nursing Review. (20 II). Being cool about the cold chain. Retrieved from http://archive.nursingreview.co.nz/issue/september-20 I I/ being-cool-about-the-cold-chain/\#.XmmOR6gzblU

Parliamentary Counsel Office. (2019). Health Practitioners Competence Assurance Act 2003. Retrieved from http://www.legislation. govt.nz/act/public/2003/0048/latest/DLM2033I2.html

Purssell, E. (2015). Reviewing the importance of the cold chain in the distribution of vaccines. British Journal of Community Nursing, 20(I0), 48I-486. https://doi.org/I0.12968/bjcn.2015.20.10.48I

Smith, T. (2019). Managing the vaccine fridge. Practice Nursing Journal, 49(5), 14-16. Retrieved from http://web.a.ebscohost.com. op.idm.oclc.org/ehost/detail/detail?vid=6\&sid=37f5d78e-05f8-44l8-aa03-c3ddc9875060\%40sdc-sessmgr03\&bdata=JnN pdGU9ZWhvc3QtbGI2ZQ\%3d\%3d\#AN=136437|74\&db=ccm

Thielmann, A., Viehmann, A., \& Weltermann, B. (20I5). Effectiveness of a web-based education program to improve vaccine storage conditions in primary care (Keep Cool): Study protocol for a randomized controlled trial. Trials, 16(30I), 1-8. https://doi.org//0.1/86/s|3063-015-0824-9

Turner, N., Laws, A., \& Roberts, L. (201I). Assessing the effectiveness of cold chain management for childhood vaccines. Journal of Primary Health Care, 3(4), 278-282. Retrieved from https://www.ncbi.nlm.nih.gov/pubmed/22132380 
Wei, H., Corbett, R., Ray, J., \& Wei, T. (2020). A culture of caring: The essence of healthcare interprofessional collaboration. Journal of Interprofessional Care, 34(3), 324-331. https://doi.org/I0.1080/13561820.2019.1641476

World Health Organization. (2020a). Cold Chain. Retrieved from https://www.who.int/countries/eth/areas/immunization/epi_ logistics/en/indexl.html

World Health Organization. (2020b). Immunisations. Retrieved from https://www.who.int/topics/immunization/en/

Youssef, D., Mearkle, R., \& Ford, K. (2020). Responding to errors in the storage, handling and administration of vaccines. Practice Nursing Journal, 3/(2), 62-69. https://doi.org/I0.12968/pnur.2020.31.2.62 